\title{
A FCyRIII-engaging bispecific antibody expands the range of HER2-expressing breast tumors eligible to antibody therapy
}

\author{
Marc Turini ${ }^{1,2,3,4}$, Patrick Chames ${ }^{1,2,3,4}$, Pierre Bruhns ${ }^{5,6}$, Daniel Baty ${ }^{1,2,3,4, *}$ and \\ Brigitte Kerfelec ${ }^{1,2,3,4, *}$ \\ ${ }^{1}$ INSERM, U1068, CRCM, Marseille, France \\ 2 Institut Paoli-Calmettes, Marseille, France \\ ${ }^{3}$ Aix-Marseille Université, UM105, Marseille, France \\ ${ }^{4}$ CNRS, UMR7258, CRCM, Marseille, France \\ ${ }^{5}$ Département d'Immunologie, Laboratoire Anticorps en Thérapie et Pathologie, Institut Pasteur, Paris, France \\ ${ }^{6}$ INSERM, U760, Paris, France \\ * Senior co-authors \\ Correspondence to: Brigitte Kerfelec, email: brigitte.kerfelec@inserm.fr \\ Keywords: bispecific antibody, breast cancer, FCYRIIIA polymorphism, HER2, trastuzumab
}

Received: March 20,2014 Accepted: June 10,2014 Published: June 11, 2014

This is an open-access article distributed under the terms of the Creative Commons Attribution License, which permits unrestricted use, distribution, and reproduction in any medium, provided the original author and source are credited.

\section{ABSTRACT}

Trastuzumab is established as treatment of HER2 $2^{\text {high }}$ metastatic breast cancers but many limitations impair its efficacy. Here, we report the design of a Fab-like bispecific antibody (HER2bsFab) that displays a moderate affinity for HER2 and a unique, specific and high affinity for FCYRIII. In vitro characterization showed that ADCC was the major mechanism of action of HER2bsFab as no significant HER2-driven effect was observed. HER2bsFab mediated ADCC at picomolar concentration against HER2 ${ }^{\text {high }}$, HER2 $^{\text {low }}$ as well as trastuzumab-refractive cell lines. In vivo HER2bsFab potently inhibited HER2 ${ }^{\text {high }}$ tumor growth by recruitment of mouse FcyRIII and IVpositive resident effector cells and more importantly, exhibited a net superiority over trastuzumab at inhibiting HER2 ${ }^{\text {low }}$ tumor growth. Moreover, FcyRIIIA-engagement by HER2bsFab was independent of V/F158 polymorphism and induced a stronger NK cells activation in response to target cell recognition. Thus, taking advantage of its epitope specificity and affinity for HER2 and FCYRIIIA, HER2bsFab exhibits potent anti-tumor activity against HER2 ${ }^{\text {low }}$ tumors while evading most of trastuzumab Fclinked limitations thereby potentially enlarging the number of patients eligible for breast cancer immunotherapy.

\section{INTRODUCTION}

Human epidermal growth factor receptor 2 (HER2) is involved in complex signaling pathways controlling cell growth, survival and proliferation depending on the triggered signaling cascades [1]. Highly overexpressed in $20-25 \%$ of breast cancers, HER2 is associated with aggressive disease, increased metastasis potential and poor clinical outcome. The humanized monoclonal antibody trastuzumab (Herceptin ${ }^{\circledR}$ ), first agent used for targeting HER2, is still standard of care as single agent [2] and in combination with chemotherapy in both early-stage and metastatic breast cancers strongly overexpressing
HER2 [3, 4]. However, despite its irrefutable benefit, a significant subset of patients $(\sim 70 \%)$ with metastatic disease shows a resistance ab initio to trastuzumab as single agent and the majority of treated patients develop resistance within one year of treatment $[5,6]$. Therefore, primary and acquired resistances to trastuzumab treatment represent an important clinical challenge. Moreover, up to now, the guidelines for trastuzumab treatment eligibility exclude patients with tumors displaying an HER2 immunohistochemistry (IHC) score of $1+/ 2+$.

Trastuzumab exerts its anti-tumor activity via the blockade of constitutive HER2 signaling and the recruitment of FcR expressing immune effector cells 
Table 1: Apparent affinities of HER2bsFab and trastuzumab for human Fc $\gamma$ receptors.

\begin{tabular}{|c|c|c|c|}
\hline & & $\begin{array}{l}\mathrm{K}_{\mathrm{R}} \text { of trastuzumab } \\
\text { (nM) }\end{array}$ & $\begin{array}{l}\mathrm{K}_{\mathrm{R}} \text { of HER } 2 \mathrm{bsFab} \\
\text { (nM) }\end{array}$ \\
\hline \multirow{10}{*}{ Human } & Fc $\gamma R I$ & $16.3+/-5.8$ & nd \\
\hline & Fc $\gamma$ RIIA-131 H & $235+/-7.1$ & nd \\
\hline & Fc $\gamma$ RIIA-131 R & $258.4+/-12.6$ & nd \\
\hline & Fc $\gamma$ RIIB & $66.7+/-4.2$ & nd \\
\hline & Fc $\gamma$ RIIC & nd & nd \\
\hline & FcyRIIIA-158 F & $194.3+/-1.5$ & $10.3+/-0.6$ \\
\hline & FcyRIIIA-158 V & $20.4+/-4.4$ & $8.7+/-0.1$ \\
\hline & FcyRIIIB / NA1 & $330+/-15.2$ & $12.3+/-0.2$ \\
\hline & FcyRIIIB / NA2 & $276.6+/-1.2$ & $8.2+/-0.6$ \\
\hline & FcyRIIIB / SH & $144.4+/-9.3$ & $7.7+/-1$ \\
\hline
\end{tabular}

Values with error bars represent mean \pm SEM. nd: no detectable binding.

responsible for antibody-dependent-cell cytotoxicity (ADCC) [7]. Although the exact contribution of each of these mechanisms in vivo is difficult to assess, pre-clinical studies provide evidence of the importance of ADCC in trastuzumab-based therapy [8-10]. The increased number of tumor-infiltrated NK cells observed in tumor tissue after trastuzumab treatment also supports the hypothesis of immune cells recruitment by the antibody $[11,12]$. Importantly, Fc $\gamma$ RIIIA-158 polymorphism has been shown to significantly influence the efficacy of trastuzumab in breast cancer patients [13]. Finally, Park et al [14] recently suggested a contribution of an adaptive immune response involving $\mathrm{CD}^{+} \mathrm{T}$ cells, dependent on the initial antibodytriggered innate response through the production of cytokines and/or danger signals by $\mathrm{FcR}^{+}$cells. However, besides FcrRIIIA-158 polymorphism, competition with endogenous IgGs and engagement of inhibitory antibody receptors (Fc $\gamma$ RIIB) have been demonstrated to drastically hinder its capacity to mediate efficient ADCC.

Consequently, tremendous efforts are ongoing either to improve the clinical efficacy of trastuzumab or to develop new strategies [15-20]. A promising alternative is the design of bispecific antibodies (bsAb) able to efficiently recruit and activate effector cells at the tumor site. After a first craze in the 90s stopped by inconsistent clinical response and immunotoxicity, a revival of interest for bispecific antibodies has emerged from the evolution in antibody engineering. This led to the development of a large number and a wide variety of bispecific formats based on either IgG or non-IgG scaffolds [21, 22]. Although retargeting of various cytotoxic effector cells is exploited, many bispecific antibodies aim at activating T-cells based on their numeric superiority and their high intrinsic toxicity, some of them being currently under clinical investigations [23-25].

FcyRIIIA positive cells are however interesting to target. In addition to their intrinsic capability to attack tumors, NK cells are not affected by the various mechanisms put in place by tumor cells to escape their recognition by $\mathrm{T}$ cells. FcyRIIIA is also expressed on monocytes and macrophages [26] that are important actors of anti tumor immunity [27]. Moreover, in contrast to CD3 targeting, FcyRIIIA targeting does not induce the recruitment and activation of Treg cells, a subset of cells able to downregulate the antitumor immunity. However, despite very encouraging in vitro or pre-clinical results, limited clinical data are available on the efficacy of Fc $\gamma$ RIII-targeting bispecific antibodies [28] and thus far, only one antibody, a bispecific TandAb targeting CD30 and Fc $\gamma$ RIIIA [29] is ongoing a clinical study [NCT01221571].

In a previous study [30], we designed a bispecific antibody based on the natural affinity of human $\mathrm{CH} 1$ and $\mathrm{C} \kappa \mathrm{IgG}$ domains as a heterodimerization motif and the unique structural and functional properties of llama single domain antibodies.

In this study, we have exploited the modular structure of the bsFab format to produce a Fab-like bispecific antibody (HER2bsFab) targeting binding sites on HER2 and FcyRIIIA different from those targeted by trastuzumab and conventional IgGs. A side by side comparison of HER $2 \mathrm{bsFab}$ with trastuzumab has been conducted in vitro and in a mouse model to characterize its anti-tumor efficacy against high- and low-HER2overexpressing, as well as trastuzumab-refractive breast cancer tumors.

\section{RESULTS}

\section{HER2bsFab binds simultaneously to HER2 and FcyRIIIA}

Based on the modular nature of the previously described compact and linker-free format [30], we designed a bsFab (HER2bsFab) targeting HER2expressing cancer cells and Fc $\gamma$ RIII positive effector cells (Fig. 1A). HER2bsFab was expressed in the periplasm of E. coli and purified to homogeneity by a two-step affinity 
chromatography procedure. HER2bsFab was produced at high yield (2-4 mg/L) and demonstrated a high stability as no significant decrease of binding was observed on SK-OV-3 or Jurkat-huFc $\gamma$ RIIIA cells after a three-week incubation at $37^{\circ} \mathrm{C}$ in non-heated human serum (Fig. S1).

The binding activity of HER2bsFab was investigated by flow cytometry on HER2 $2^{\text {high }}$ breast cancer cells (SK-
BR-3 and BT 474) and human FcyRIIIA-transfected Jurkat cells (Fig. 1B-C). HER2bsFab efficiently bound all cell lines as more than $90 \%$ of cells were positively stained. Worth mentioning, no binding was detected on the nontumorigenic mammary epithelial cell line, hTERT-HME1, which expresses a basal level of HER2 (Fig. 1B, right panel). Relative to trastuzumab, HER2bsFab displayed a
A

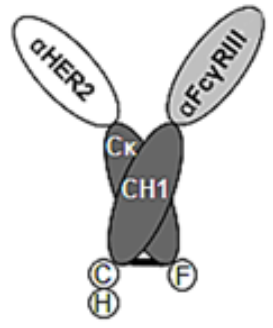

C

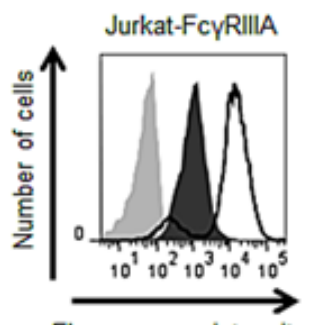

Fluorescence intensity

Control

HER2bsFab

\section{B}

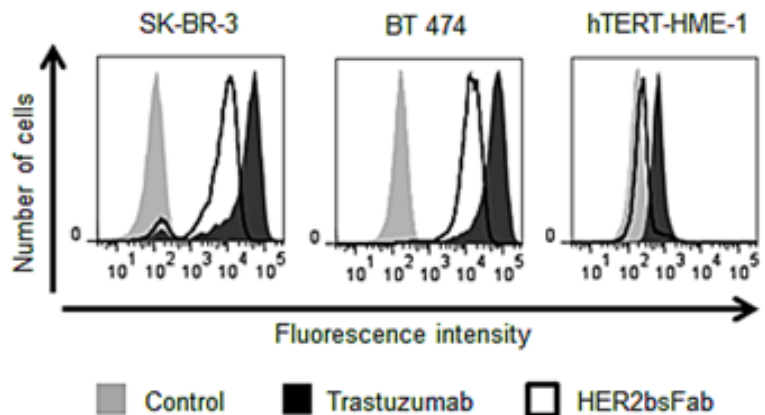

D

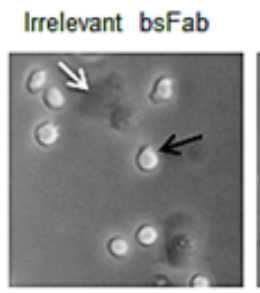

Trastuzumab
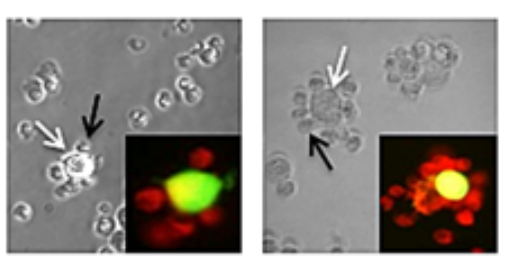

E

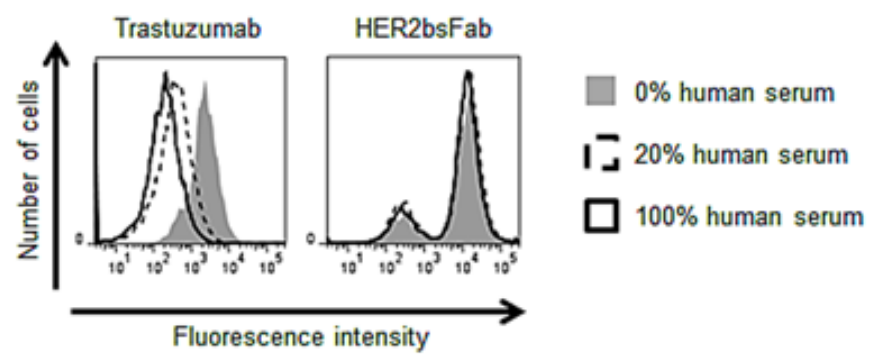

Figure 1: HER2bsFab simultaneously binds to cell surface HER2 and Fc $\gamma$ RIIIA. A) Schematic representation of the

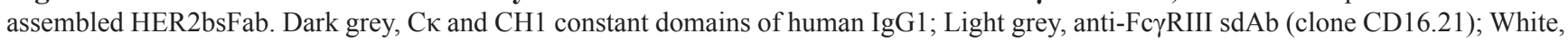
anti-HER2 sdAb (clone HER2.C7b); C, 6H and F, c-myc, hexahistidine and Flag Tag respectively. Binding of biotinylated HER2bsFab and trastuzumab (100 nM) to B) HER2-positive (SK-BR-3, BT 474), HER2-negative (hTERT-HME-1) or C) Fc $\gamma$ RIIIA expressing JurkathuFc $\gamma R$ RIIIA cells was analyzed by flow cytometry. PE-labeled streptavidin was used for detection. D) Rosette forming cells assay: CFSE labeled SK-OV-3 (white arrows) and Red CMTPX labeled Jurkat-huFcyRIIIA (black arrows) cells were co-cultured with irrelevant bsFab, HER $2 \mathrm{bsFab}$ or trastuzumab $(40 \mathrm{nM})$ and rosette formation was observed by optical and fluorescent microscopy. Representative images of different conditions are shown. E) Competition assay with endogenous IgG: Jurkat-huFc $\gamma$ RIIIa cells were incubated with biotinylated HER $2 \mathrm{bsFab}(50 \mathrm{nM})$ or trastuzumab $(200 \mathrm{nM})$ in presence of various concentrations of human serum. Bound antibodies were detected using PE-labeled streptavidin. 
lower apparent affinity $(80.1+/-13 \mathrm{nM}$ vs. $6.8+/-0.6 \mathrm{nM})$ for HER2 partly explained by its monovalency. Binding of HER2bsFab was determined on all human Fc $\gamma R$ using CHO cells expressing FLAG-tagged Fc $\gamma$ R (Table 1). Expression levels of Fc $\gamma \mathrm{R}$ were checked by labeling cells with anti-FLAG. Unlike trastuzumab which bound to all Fc $\gamma$ R except Fc $\gamma$ RIIC, HER2bsFab bound only to Fc $\gamma$ RIIIA and B. Regarding Fc $\gamma$ RIIIA, trastuzumab binding was variable according to the Fc $\gamma$ RIIIA-158 allotypes, with a 10-fold lower affinity for Fc $\gamma$ RIIIA-158 F/F while HER2bsFab exhibited similar and high apparent affinities for both FcyRIIIA-158 allotypes. The dual specific binding of HER2bsFab to HER2 and Fc $\gamma$ RIIIA was demonstrated by its capacity to induce, in vitro, the formation of rosettes of Jurkat-huFc $\gamma$ RIIIA cells around HER2-positive SK-OV-3 cells (Fig. 1D). No rosette forming cells were observed when an irrelevant bsFab targeting Fc $\gamma$ RIII but not HER2 was used. Furthermore, consistent with the targeting of an original Fc $\gamma$ RIIIA epitope [31], we confirmed that, contrary to trastuzumab,
HER2bsFab did not compete with endogenous serum IgG for binding to Fc $\gamma$ RIIIA (Fig. 1E), strongly suggesting that HER2bsFab must escape competition with serum IgG in vivo.

\section{HER2bsFab does not inhibit cell growth}

Anti-proliferative effects of HER2bsFab were determined by following SK-BR-3 cell growth for 3, 5 and 7 days in the presence of HER2bsFab or trastuzumab. No inhibitory effect of HER2bsFab was observed on SKBR-3 cell growth while a time-dependent inhibition was achieved in the presence of trastuzumab, the maximal growth inhibition reaching about $45 \%$ after 7 days (Fig. 2A). In an attempt to explain why HER2bsFab had no anti-proliferative effect, we analyzed the impact of HER 2 bsFab on the activation of downstream MAPK and $\mathrm{PI} 3 \mathrm{~K} / \mathrm{AKT}$ signaling pathways as these molecular events reflect HER2 activity (Fig. 2B). After an $8 \mathrm{hr}$-incubation

A

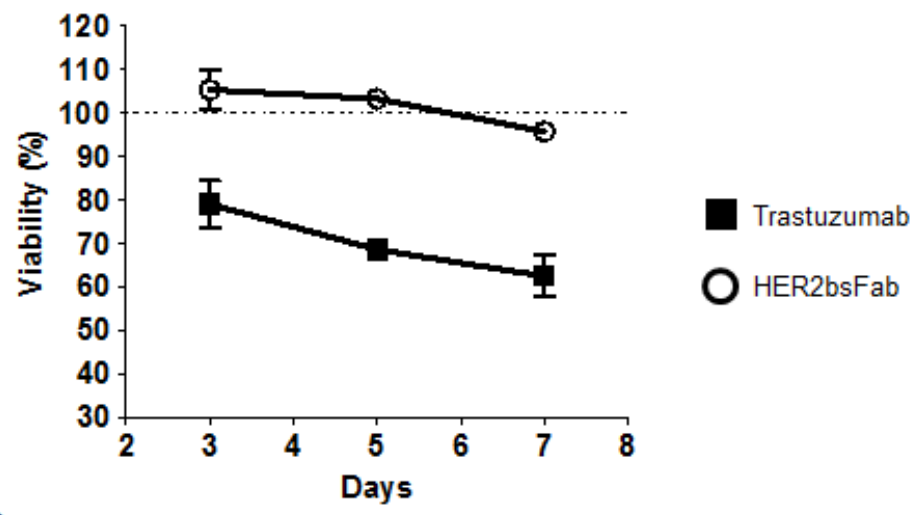

B
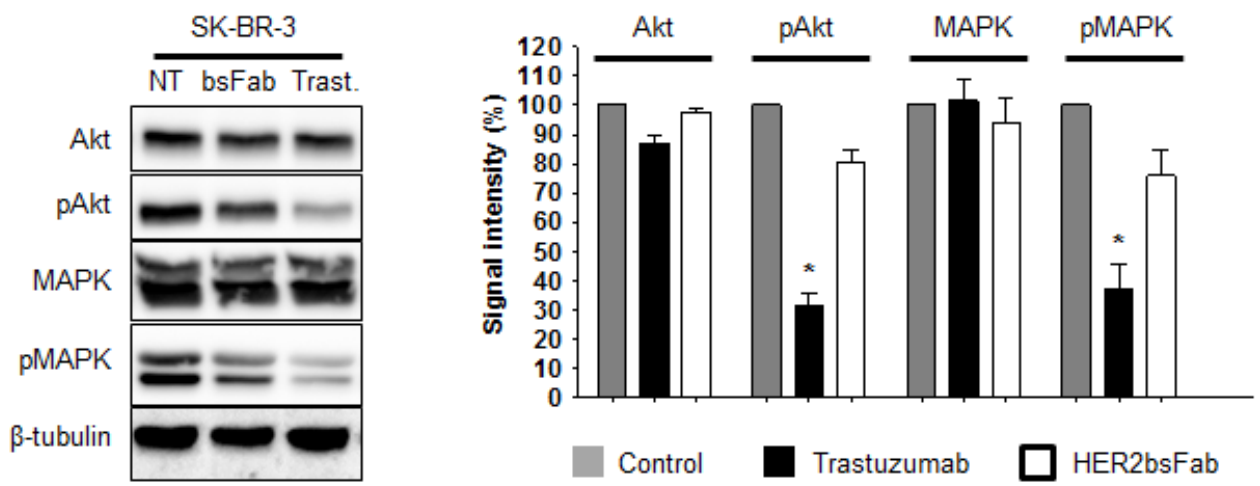

Figure 2: Anti-proliferative effects mediated by trastuzumab and HER2bsFab. A) SK-BR-3 cells growth was followed for 3,5 and 7 days in the presence of trastuzumab or HER2bsFab $(500 \mathrm{nM})$. Cell viability was quantified using CellTiter Glo viability assay. Results are shown as percentage of control cell proliferation and expressed as mean \pm SEM. All procedures were done in triplicate. B) Immunoblots evaluating the ability of HER2bsFab and trastuzumab (200 nM) to inhibit MAPK and Akt signalling pathways in SK-BR-3 cells (incubation time: $8 \mathrm{~h}$ ). Medium alone was used as a control. The experiments were performed three times. NT: non treated; Trast: trastuzumab; bsFab: HER2bsFab. Immunoblots were quantified using the NIH Image J software after correction for $\beta$-tubulin. Values are expressed as percentage of non treated cells signal. Values with error bars represent mean \pm SEM. Data were analyzed by Student's t-test. $* P<0.05$ vs. non treated controls. 
with either $200 \mathrm{nM}$ HER2bsFab or trastuzumab, SK-BR-3 cell lysates were submitted to western blot analysis. While the levels of total MAPK and PI3K-Akt proteins were not modified, low but detectable changes in both pMAPK and pAkt levels were observed relative to untreated cells, upon HER2bsFab treatment (20-25\%). As expected, a strong diminution of pMAPK and pAkt levels was observed in the presence of trastuzumab (60-70\%). These results suggest that the slightly reduced activation of downstream intracellular pathways induced by HER2bsFab on SK-
BR-3 cells was no sufficient to induce an inhibition of cell growth.

\section{HER2bsFab mediates potent NK cell cytotoxicity against HER2 ${ }^{\text {high }}$ breast cancer cells in vitro}

The capacity of HER2bsFab to trigger tumor cell lysis by retargeting NK cells was investigated in vitro using a luminescent ATP-assay, as a nonradioactive alternative to

A

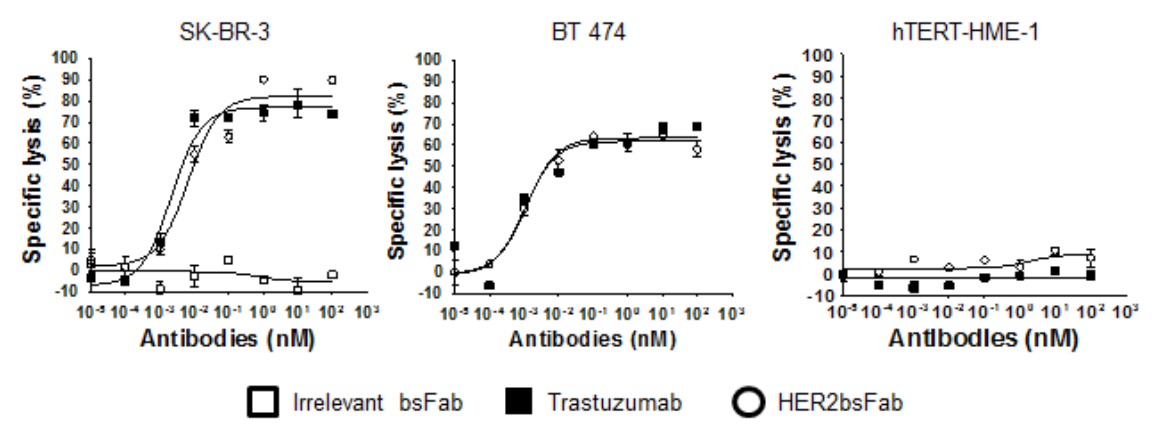

B
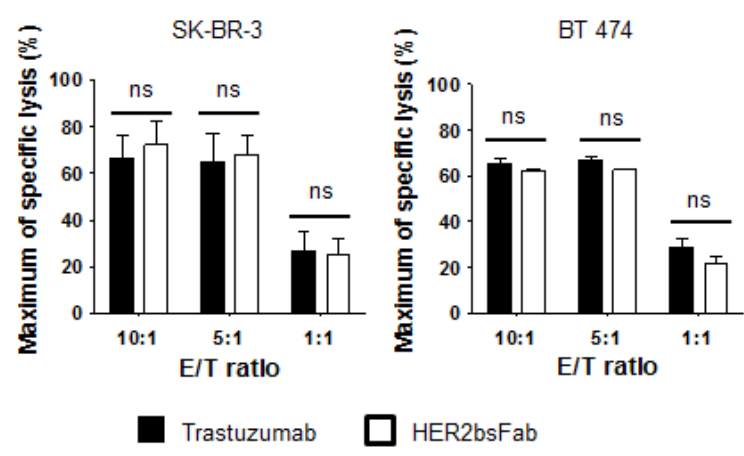

C

D
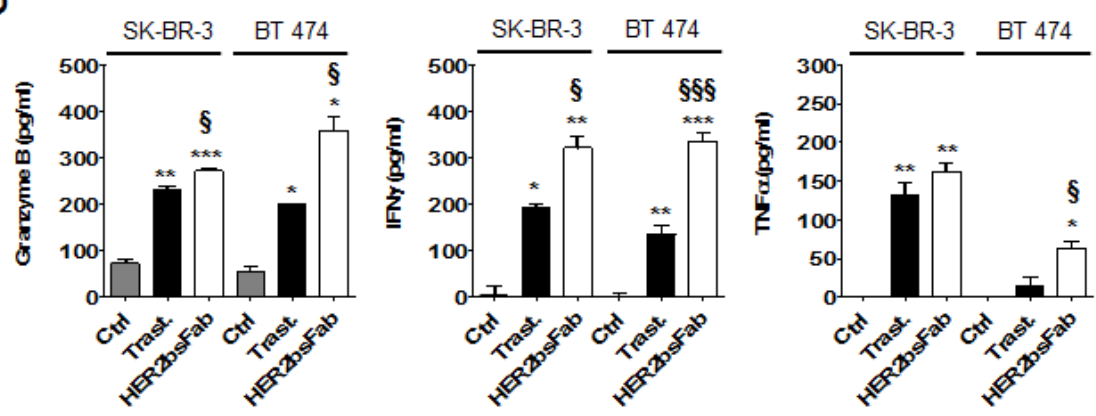

Figure 3: HER2bsFab mediates potent in vitro ADCC activity similar to trastuzumab against high-HER2-overexpressing cells. A) ADCC assays were performed using human NK cells as effector cells and SK-BR-3, BT 474 or hTERT-HME-1 as target cells (E/T 10:1) in the presence of irrelevant bsFab, HER2bsFab or trastuzumab. Target cell viability was measured by CellTiter-Glo viability assay. Results are representative of at least three independent donors. Mean values \pm SEM are presented. B) Impact of the E/T ratios on SKBR-3 and BT 474 cells lysis mediated by HER2bsFab or trastuzumab (100 nM). Data are representative of two experiments performed in triplicate, and represent the mean \pm SEM. ns: non significant. C) Activation status of NK cells harvested from cytotoxicity assays illustrated in A) assessed for CD69 expression, detected with APC-conjugated anti-CD69. Secretions of D) granzyme B, E) IFN $\gamma$ and F) TNF $\alpha$ were quantified by ELISA in supernatants from cytotoxicity assays against SK-BR-3 and BT 474 cells illustrated in A). Data are representative of at least two experiments performed in triplicate, and represent the mean \pm SEM. Data were analyzed by Student's t-test. * $P<0.05$ vs. control; ** $P<0.01$ vs. control; $* * * P<0.001$ vs. control; $\S P<0.05$ vs. trastuzumab; Ctrl: Control; Trast: trastuzumab. 
the conventional $\mathrm{Cr}^{51}$ assay. Figure 3 shows representative results using purified unstimulated human NK cells from a healthy donor as effector cells and HER2 ${ }^{\text {high }}$ breast cancer cells (SK-BR-3 and BT 474) or hTERT-HME1 as target cells (Fig. 3A). Very similar dose-dependent curves were obtained with trastuzumab and HER2bsFab at E/T ratio of 10:1 (Fig. 3A, left and middle panels) with comparable maximal levels of lysis (efficacy) of about $60-80 \%$ and similar $\mathrm{EC}_{50}$ values (potency) (2-6 pM). Since no growth inhibition was detected after overnight incubation of HER2 ${ }^{\text {high }}$ cancer cells with saturating concentrations of trastuzumab or HER2bsFab, cell lysis was directly correlated to ADCC. Importantly, no NK cytotoxic activity was observed when an irrelevant bsFab that elicited a cytolytic response in different experimental settings [30] or when hTERT-HME-1 cells were used (Fig. 3A, right panel). Lowering the $\mathrm{E} / \mathrm{T}$ ratio down to $1: 1$ resulted in a significant but similar reduction of lysis to about $30 \%$ both for trastuzumab and HER2bsFab (Fig. 3B), indicating that HER2bsFab remained at least as efficient as trastuzumab at low $\mathrm{E} / \mathrm{T}$ ratios.

To assess that HER2bsFab-mediated lysis was correlated to Fc $\gamma$ RIIIA engagement, the activation state of NK cells, harvested from ADCC assay against SKBR-3 cells (E/T 10:1), was evaluated by following the expression of the activation marker CD69 by flow cytometry (Fig. 3C). No significant up-regulation of CD69 was observed in the presence of the irrelevant bsFab confirming that NK cells activation was strictly dependent on the dual engagement of both receptors. The proportion of activated NK cells was slightly higher with HER2bsFab (77\%) than with trastuzumab (61\%), maybe due to its higher Fc $\gamma$ RIIIA-affinity. Secretion of granzyme B, a key cytotoxic molecule released by activated NK cells, was also quantified in supernatants harvested from ADCC assays against SK-BR-3 and BT 474 cells (Fig. 3D, left panel). Consistent with the results obtained with CD69, we found that HER2bsFab induced a granzyme B release moderately but significantly higher compared with trastuzumab. Finally, as effective antitumor immune responses are known to require the secretion of inflammatory cytokines such as IFN $\gamma$ or TNF $\alpha$, the ability of HER2bsFab to induce cytokines release in response to target cells was investigated (Fig. 3D, middle and right panels). Measurements of extra cellular INF $\gamma$ and TNF $\alpha$ performed on ADCC supernatants showed that NK cells secreted higher amount of both cytokines in response to bsFab-coated SK-BR-3 and BT 474 cells compared with trastuzumab-coated cells. Taken together, these results demonstrated that, through dual engagement of HER2 and Fc $\gamma$ RIIIA, HER2bsFab is able to strongly activate NK cells, leading to a potent and highly specific cytotoxicity toward high-HER2-overexpressing tumor cells and the secretion of pro-inflammatory cytokines.

\section{HER2bsFab mediates potent in vitro ADCC against both trastuzumab refractive and low- HER2-overexpressing breast cancer cells.}

We next determined whether enhanced affinity for Fc $\gamma$ RIIIA could be translated into increased ADCC activity against trastuzumab-refractive and low-HER2overexpressing breast cancer cell lines. To support this hypothesis, we evaluated the cytotoxic activity of HER2bsFab against two different breast cancer cell lines, MCF-7 which weakly overexpresses HER2 and JIMT-1 which, although overexpressing HER2, displayed a low trastuzumab-binding capacity due to overexpression of mucin 4 (MUC4) [32].

The mean number of accessible HER2 binding sites (specific antigen binding capacity, SABC) of the different cell lines was first estimated by the Dako QIFIKIT ${ }^{\circledR}$ (Fig. 4A). According to the consensual clinical classification of HER2 expression in tumors, MCF-7 cells (HER2 $2^{\text {low } /}$ IHC score 1+) weakly overexpressed HER2 with a SABC ( 7,260 sites/cell) significantly lower than SK-BR-3 or BT 474 cells (HER2 ${ }^{\text {high/ }}$ IHC score $3+$, SABC $>400,000$ sites/cell) but still significantly higher than hTERT-HME1 cells (SABC $\sim 127$ sites/cell). In accordance with the results described by Nagy et al. [33], and despite similar number of HER2 gene copies, the amount of accessible HER2 receptors at the surface of JIMT-1 cells (SABC $\sim 53,800$ ) appeared to be about 8 to 10 -fold lower than that determined for the two HER2 ${ }^{\text {high }}$ cancer cells, due to overexpression of MUC4. Consistent with these results, JIMT-1 and MCF-7 cells displayed a significantly weaker labeling with both trastuzumab and HER2bsFab compared to SK-BR-3 or BT 474 cells (Fig. 4B). Nevertheless, HER2bsFab binding activity still remained efficient on these two cell lines as more than $90 \%$ of cells were labeled in each case.

Cytotoxic assays were then performed, using purified resting human NK cells and E/T ratio of 10:1 (Fig. 4C). As expected, trastuzumab triggered low levels of ADCC against MCF-7 and JIMT-1 cells (40 and 38\% respectively). By contrast, HER $2 \mathrm{bsFab}$ demonstrated high cytotoxic activity on both cell lines, with maximum rates of specific lysis of $78 \%$ and $62 \%$ respectively. Interestingly, the higher ADCC potential of HER2bsFab against MCF-7 cells remained evident at the three E/T ratios tested (Fig. 4D, right panel). On the contrary, the difference in ADCC activity against JIMT-1 cells between the two antibodies faded at the lowest E/T ratio (Fig. 4D, left panel).

We subsequently measured the release of granzyme $\mathrm{B}$ and pro-inflammatory cytokines in the supernatants harvested from above ADCC assays (Fig. 5). As could be expected from the decrease of trastuzumab efficiency, the amounts of granzyme B and pro-inflammatory cytokines released during trastuzumab-driven ADCC against both 
MCF-7 and JIMT-1 cells were rather low, not always reaching significance over spontaneous release. Likewise, granzyme release and cytokine secretion by NK cells were also impaired in response to HER2bsFab-coated cells, albeit to a lesser extent. This finding, in line with those obtained with high-HER2-overexpressing cells, supported the idea that HER2bsFab is more potent than trastuzumab for inducing NK cell activation whatever the level of
HER2 expression.

HER2bsFab mediates in vivo antitumor responses against both HER2 ${ }^{\text {high }}$ and trastuzumab-refractive tumors

Before investigating the therapeutic activity of the two antibodies in mouse models, their binding to
A

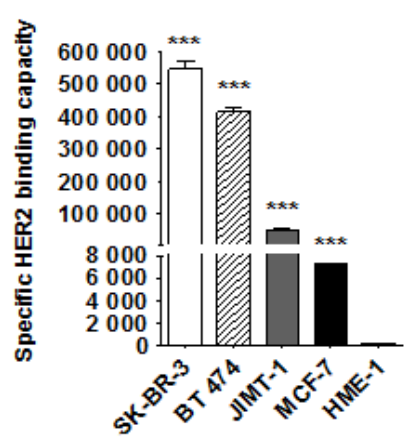

C

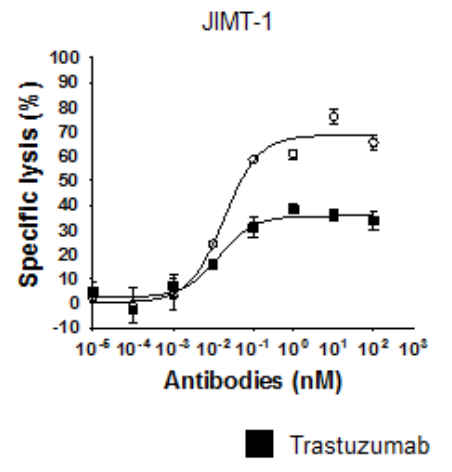

D

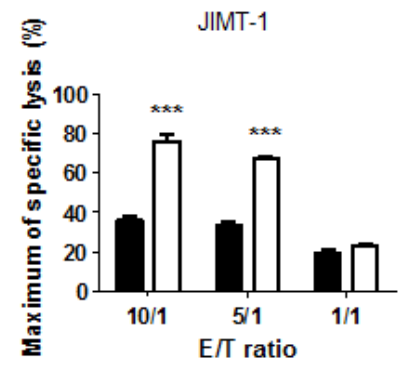

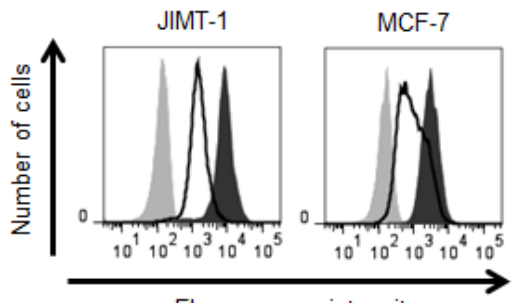

Fluorescence intensity

Control
Trastuzumab HER2bsFab
MCF-7

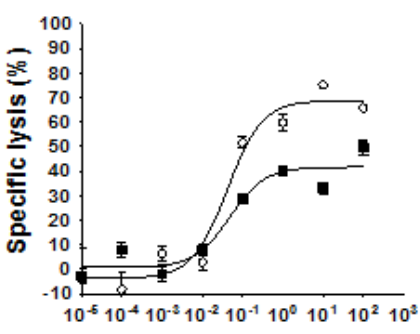

Antibodies ( $\mathrm{nM}$ )

HER2bsFab

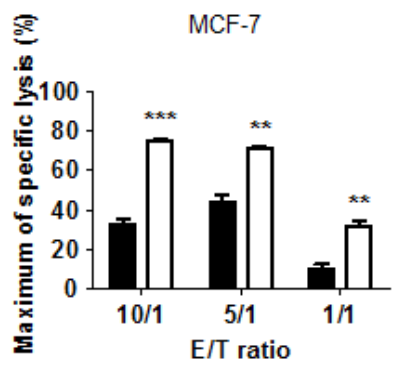

Trastuzumab $\square$ HER2bsFab

Figure 4: In vitro, HER2bsFab induces potent ADCC against low-HER2-overexpressing and trastuzumab refractive cells. A) Specific HER2 binding capacities of SK-BR-3, BT 474, JIMT-1, MCF-7 and hTERT-HME-1 cells were assessed by DAKO QIFIKIT. Values with error bars represent mean \pm SEM. Data were analyzed by Student's t-test. *** $P<0.001$ vs. HME- 1 cells. B) Binding of isotype control, biotinylated trastuzumab or biotinylated HER2bsFab to JIMT-1 or MCF-7 cells. Bound antibodies were detected using PE-labeled streptavidin. C) ADCC assays were performed using JIMT-1 or MCF-7 cells as target cells and human NK cells as effector cells (E/T 10:1) and HER2bsFab or trastuzumab. Target cell viability was measured by CellTiter Glo viability assay. Results are representative of at least three independent donors. Values with error bars represent mean \pm SEM. D) Impact of the E/T ratios on JIMT-1 or MCF-7 cells lysis mediated by HER2bsFab or trastuzumab $(100 \mathrm{nM})$ cells. Values with error bars represent mean \pm SEM and are representative of two experiments performed in triplicate. Data were analyzed by Student's t-test. ** $P<0.01$ vs. trastuzumab; *** $P<0.001$ vs. trastuzumab. 
murine Fc $\gamma \mathrm{R}$ was checked by flow cytometry on stably transfected $\mathrm{CHO}$ cells expressing FLAG-tagged murine Fc $\gamma R$ (Table 2). As expected, trastuzumab bound all four murine activating and inhibiting Fc $\gamma R$, with apparent affinities ranging from 46 to $309 \mathrm{nM}$, while HER2bsFab only recognized Fc $\gamma$ RIII and Fc $\gamma$ RIV $\left(K_{D} \sim 20 \mathrm{nM}\right)$. These results were consistent with those on immune effector cells collected from spleen of nude mice demonstrating that both antibodies were able to bind on murine macrophages, monocytes, NK cells and neutrophils (Fig. S2).

Knowing that HER2bsFab interacts with mouse resident immune cells, HER2bsFab in vivo activity was examined using HER2 ${ }^{\text {high }}$ (BT 474), HER2 ${ }^{\text {low }}$ (MCF-7) and trastuzumab-refractive (JIMT-1) xenograft models. BT 474 cells were chosen as SK-BR-3 cells have been reported to poorly form xenograft in athymic mice [34]. Athymic NMRI Nude mice were injected with $10^{7}$ cells subcutaneously and treatments were started once tumors reached about $180-250 \mathrm{~mm}^{3}$. Irrelevant $\mathrm{bsFab}$ and HER2bsFab were injected i.p. at $5 \mathrm{mg} / \mathrm{kg}$ three times per week while trastuzumab was injected at the same dose two

A
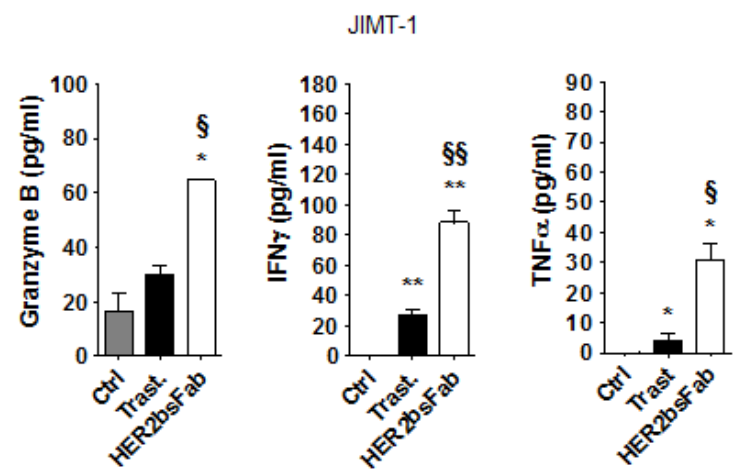

B

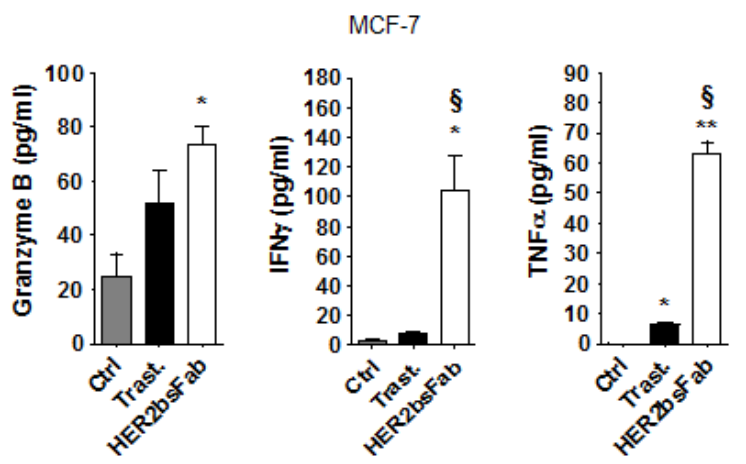

Figure 5: HER2bsFab efficacy against trastuzumabrefractive cells acts through an efficient activation of NK cells. NK activation was assessed by evaluating secretion of granzyme B, IFN $\gamma$ and TNF $\alpha$ in supernatants of cytotoxicity assays on A) JIMT-1 and B) MCF-7 cells by ELISA. Measurements were performed in triplicate. Values with error bars represent mean \pm SEM. Data were analyzed by Student's t-test. $* P<0.05$ vs. control; ${ }^{* *} P<0.01$ vs. control; $\S P<0.05$ vs. trastuzumab; $\S \S P<0.01$ vs. trastuzumab. times per week. In all xenograft models, a 100\% tumortake was reached and no adverse effects on body weight or general behavior were observed for all treated mice.

As shown in Figure 6A, HER2bsFab displayed a potent anti-tumor activity comparable to that of trastuzumab against BT 474 cells, as evidenced by the statistically different size of tumors between controls (PBS and irrelevant bsFab) and treated groups. Importantly, no significant difference was observed between control

A

BT 474

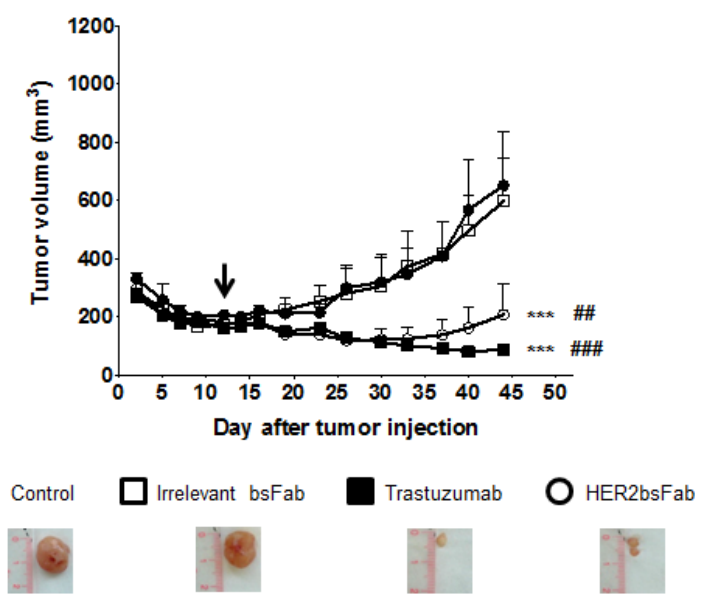

B

MCF-7

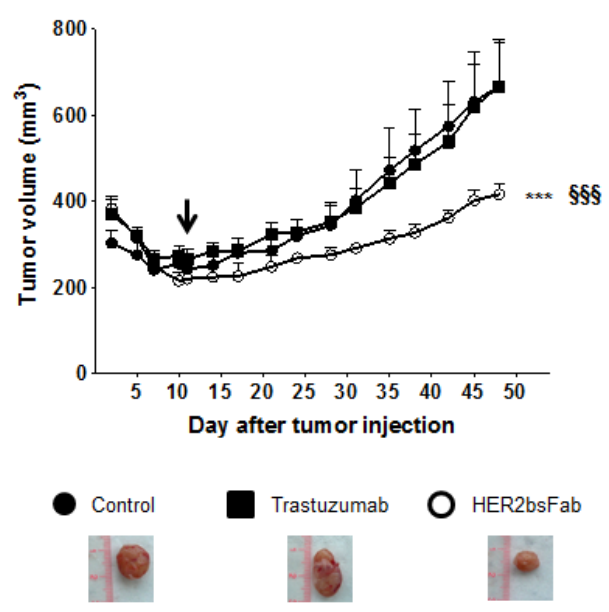

Figure 6: In vivo anti-tumor activity of HER2bsFab. All tumors were xenografted subcutaneously in NMRI Nude mice. Tumor volumes of A) BT 474 or B) MCF-7 tumors were measured after treatment with irrelevant bsFab $(5 \mathrm{mg} / \mathrm{kg})$, HER2bsFab ( $5 \mathrm{mg} / \mathrm{kg}$ ), PBS (control buffer) or trastuzumab $(5 \mathrm{mg} / \mathrm{kg})$. Values with error bars represent mean \pm SEM. Data were analyzed by One way ANOVA test. $* * * P<0.001$ vs. control buffer group; \#\#\# $P<0.001$ vs. irrelevant bsFab group; \#\# $P<0.01$ vs. irrelevant bsFab group; $\S \S \S P<0.001$ vs. trastuzumab group. Beginnings of treatments were illustrated by black arrows. Representative images of tumors treated with negative controls, trastuzumab or HER2bsFab are illustrated for each model. 
Table 2:Apparent affinities of HER2bsFab and trastuzumab for mouse Fc $\gamma$ receptors.

\begin{tabular}{|l|l|l|}
\hline & $\begin{array}{l}\mathrm{K}^{\mathrm{D}} \text { of trastuzumab } \\
(\mathrm{nM})\end{array}$ & $\begin{array}{l}\mathrm{K}^{\mathrm{D}} \text { of HER2bsFab } \\
(\mathrm{nM})\end{array}$ \\
\hline Fc $\gamma$ RI & $110.5+/-11.8$ & $\mathrm{nd}$ \\
\hline Fc $\gamma$ RIIB & $309.1+/-27.9$ & nd \\
\hline Fc $\gamma$ RIII & $198.2+/-4.5$ & $17.2+/-0.58$ \\
\hline Fc $\gamma$ RIV & $46.3+/-1.2$ & $26.4+/-2$ \\
\hline
\end{tabular}

Values with error bars represent mean \pm SEM. nd: no detectable binding.

buffer and irrelevant bsFab suggesting that the antitumor response produced by HER2bsFab is specific to HER2 recognition. Regarding the JIMT-1 xenograft model, trastuzumab moderately but significantly delayed JIMT-1 tumor progression compared with the non-treated group (Fig. S3). HER2bsFab also tended to delay tumoral growth without, however, reaching a significant benefit over the control group. By contrast, HER2bsFab treatment significantly reduced MCF-7 tumor growth in comparison to PBS while no tumor growth delay was observed in tumor-bearing mice treated with trastuzumab (Fig. 6C). Altogether, these data demonstrated that, relative to trastuzumab, HER 2 bsFab displayed significant benefit for treating both in vitro and in vivo tumors overexpressing only weakly HER2.

\section{FcyRIIIA-158 F/V polymorphism has no incidence on in vitro cytotoxic activity of HER2bsFab against HER2 ${ }^{\text {low }}$ tumor cells}

As these promising pre-clinical results suggested potential clinical interest in extending the proportion of treatable HER2 breast cancers, one important issue to

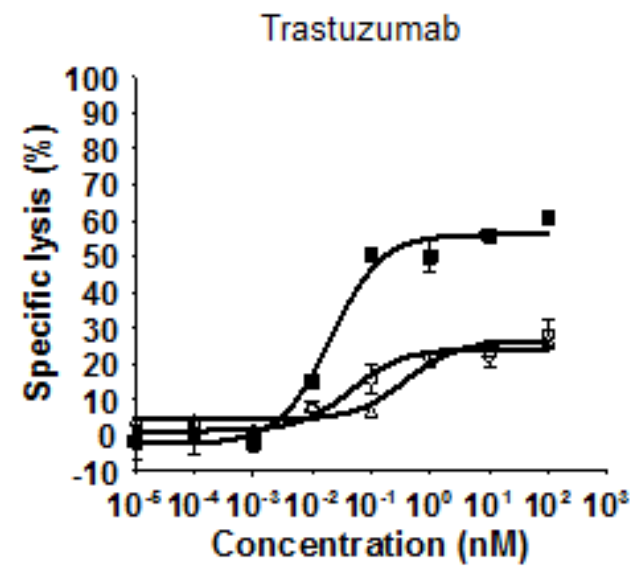

FcyRIIIA-158 V/N $\quad$ O FcyRIIIA-158 V/F look at was the absence of influence of the Fc $\gamma$ RIIIA-158 $\mathrm{F} / \mathrm{V}$ polymorphism in the case of tumors overexpressing only weakly HER2. Indeed, it has been shown that the Fc $\gamma$ RIIIA-158 F/V and F/F allotypes, present in more than $80 \%$ of the caucasian population [13], are associated with worse clinical response upon trastuzumab treatment. In this respect, we showed that HER2bsFab-triggered ADCC against HER2 $2^{\text {low }}$ MCF-7 cells using NK cells from Fc $\gamma$ RIIIA-158 V/V, F/F or V/F donors (E/T 5:1) was not affected by the FcrRIIIA-158 polymorphism as $\mathrm{EC}_{50}$ values ranged from 44 to $56 \mathrm{pM}$ and maximal lysis, from 52 to $57 \%$ whatever the Fc $\gamma$ RIIIA-158 allotype (Fig. 7). By contrast, as expected, both the potency and the efficacy of trastuzumab were significantly modulated according to Fc $\gamma$ RIIIA-158 allotype.

\section{DISCUSSION}

Trastuzumab represents the archetype of clinically effective targeted immunotherapy of solid tumors, as it has contributed to real improvements in the outcome of metastatic breast cancer strongly overexpressing HER2. However, significant subsets of patients do not benefit from trastuzumab treatment due either to primary

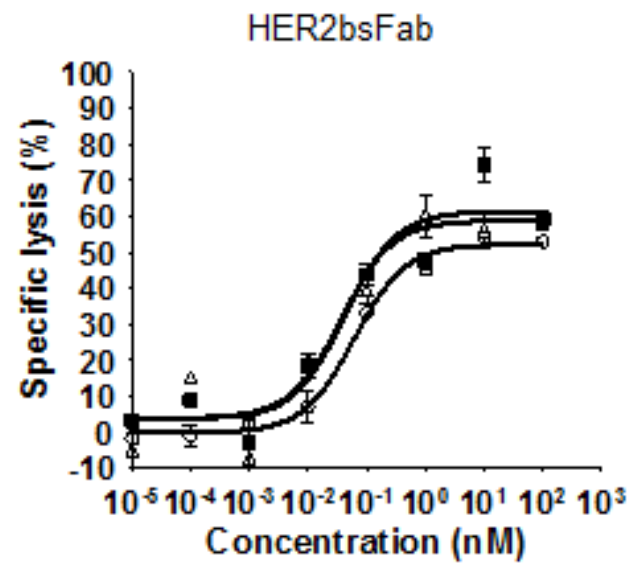

$\Delta$ FcyRIIIA-158 F/F

Figure 7: Effect of FcyRIIIA polymorphism on the ADCC triggered by HER2bsFab. ADCC assays were performed using human Fc $\gamma$ RIIIA-158 V/V, F/V or F/F NK cells as effector cells and MCF-7 as target cells (E/T 5:1) in the presence of various concentrations of trastuzumab or HER2bsFab. All experiments were performed two times in triplicate. Values with error bars represent mean $\pm \mathrm{SEM}$. 
resistance, to relapse during the course of treatment due to acquired resistance or to low HER2 IHC score $[5,6]$. Besides the limitations related to its own characteristics, trastuzumab also suffers from the disadvantages of IgG antibodies, namely Fc $\gamma$ RIIIA-158 polymorphism of NK cells [13], competition with endogenous IgG [35], binding on inhibitory receptor Fc $\gamma$ RIIB [36] and Fc fucosylation issues [37]. Thus, considerable efforts are currently made to optimize the effector function of trastuzumab mainly through removal of fucose glycosylation [15] or through mutations to overcome the polymorphism issues [16, 38]. However, although improving Fc $\gamma$ RIIIA binding in a significant way, these strategies do not fully bypass the limitation of inhibitory Fc $\gamma$ RIIB binding [16].

Another promising strategy is the development of bispecific antibodies able to recruit and activate various immune effector cells at the tumor site. Several anti-HER2 bispecific antibodies targeting neutrophils, monocytes, and macrophages via Fc $\gamma$ RI [39], T-cells via CD3/CD28 [40-42] or NK cells via FcyRIIIA $[43,44]$ have been designed. However, despite encouraging in vitro and preclinical results, only one bispecific antibody targeting CD3 [42] is under clinical trial, highlighting the need to improve further the design of these molecules. Using our versatile Fab-like bispecific antibody format [30] based on the use of llama single domain antibodies, we developed a bispecific antibody, named HER2bsFab, that targets human HER2 antigen and activating Fc $\gamma$ RIIIA receptor.

Consistent with our previous studies [30], HER2bsFab was well produced in E. coli and highly stable due to the absence of linker. Compared to optimized Fc formats, HER2bsFab displays unique and interesting features. It is selective for Fc $\gamma$ RIII as no binding to Fc $\gamma R I$, Fc $\gamma$ RIIA or inhibitory receptor Fc $\gamma$ RIIB was observed. Moreover, it binds the Fc $\gamma$ RIIIA receptor with an apparent affinity 36-fold higher than trastuzumab, targeting an epitope outside the Fc $\gamma$ binding site [31], thus bypassing competition with endogenous IgG. HER2bsFab specifically binds to an epitope of the extracellular domain of HER2 that is different from that of trastuzumab [45], with an intermediate affinity $(60 \mathrm{nM})$. This feature might be an advantage over trastuzumab as several studies have described the existence of a binding site barrier that limits tumor penetration of high affinity antibodies [46, 47]. As well, Cao et al. [48] recently reported that high affinity scFv antibody-based immunotoxins induced more hepatotoxicity than their low affinity counterparts, due to an important formation of immune complexes with soluble shed tumor antigen. An intermediate affinity for the well known shed extracellular domain of HER2 could avoid such side effects.

Exploration of in vitro direct HER2-driven properties of HER2bsFab showed that, unlike trastuzumab, HER2bsFab had no anti-proliferative activity on HER2 ${ }^{\text {high }}$ SK-BR-3 cell, despite a minor effect on downstream MAPK and PI3K/Akt signaling pathways. This result could be explained by either the epitope specificity of HER2bsFab, its monovalency and/ or its intermediate affinity for HER2 as we demonstrated that the same anti-HER2 sdAb produced in a bivalent format ( $\mathrm{Fc}$ fusion, apparent $\mathrm{K}_{\mathrm{D}}$ of $2 \mathrm{nM}$ ), showed an anti-proliferative effect $(30 \%)$ at high concentration. As ADCC and signaling effects occur independently [49], the absence of anti-proliferative effects of HER2bsFab should not be detrimental for in vivo anti-tumor activity and could avoid the development of resistance related to upregulation of alternative signaling pathways and/or to altered intracellular signaling observed upon long-term exposure to trastuzumab $[50,51]$.

We showed that HER2bsFab-mediated ADCC against HER2 ${ }^{\text {high }}$ breast cancer cells was similar to that of trastuzumab both in terms of efficacy (maximal lysis) and potency $\left(\mathrm{EC}_{50}\right)$, even at low $\mathrm{E} / \mathrm{T}$ ratio $(1: 1)$. Worth mentioning, HER2bsFab retained its high ADCC activity at picomolar concentration using unstimulated human PBMC as effectors (E/T: 25/1, Fig. S4). The presence of neutrophils in vitro did not appear to modify the killing efficacy of HER2bsFab, in agreement with previously published data [52] (Fig. S5). The analysis of ADCC pathway showed that, through FcyRIIIA engagement, HER2bsFab, as trastuzumab, induces a perforin-mediated cytotoxicity, stimulating NK cell degranulation and cytokine secretion in response to target cell recognition. Fauriat et al [53] have shown that different thresholds exist in activating signals to induce NK cell effector responses: chemokine secretion requires the lowest activating signals, moderate ones induce degranulation and the strongest ones induce cytokine secretion. Interestingly, relative to trastuzumab, HER2bsFab elicited a higher level of secreted IFN $\gamma$ suggesting that HER2bsFab induces a stronger NK activation signal. This finding was consistent with the slightly greater percentage of CD69 positive NK cells and the much higher level of granzyme B, further emphasizing the substantial difference in FcyRIIIA engagement between HER2bsFab and trastuzumab, likely due to more stable crosslinking of Fc $\gamma$ RIIIA by HER2bsFab. However, despite the higher NK activation mediated by HER2bsFab, no difference in maximum lysis was observed compared with trastuzumab against both SK-BR-3 and BT 474 cells. One explanation could be that the high HER2 density displayed by these cell lines shades off the differences in affinity for both HER2 and Fc $\gamma$ RIIIA between the two antibodies, the bivalence of trastuzumab against HER2 compensating its low affinity for Fc $\gamma$ RIIIA.

The more potent effector functions mediated by HER2bsFab raise the hypothesis that HER2bsFab could potentially be beneficial in a context of trastuzumabrefractive and low-HER2-overexpressing breast cancers. To address this question, we analyzed the in vitro efficacy of HER2bsFab against two models of trastuzumab refractive breast cancers: MCF-7, an HER2 non-amplified cell line not eligible to trastuzumab treatment due to 
a weak HER2 overexpression, and JIMT-1, a model of HER2-overexpressing, trastuzumab resistant cell line. Several mechanisms are likely underlying JIMT-1 resistance among which (i) a partial masking of HER2 by overexpressed MUC4 [33] and (ii) the absence of HER2driven effects of trastuzumab [54]. The absence of antiproliferative effects of either trastuzumab or HER2bsFab on these two cell lines allowed a direct comparison of their ADCC capacity.

For sake of comparison between cell lines and because heterogeneous data are found in the literature regarding the HER2 status of $\mathrm{MCF}-7$, maybe due to biological differences among MCF-7 cell lines [55], the HER2 binding capacity of all cell lines tested was assessed. We thus confirmed that MCF-7 cells displayed a low but significant HER2 overexpression (SABC 60fold higher than that of hTERT-HME-1 cells) despite an absence of gene amplification. We show in this study that in vitro, HER2bsFab retained its full killing efficacy against both JIMT-1 and MCF-7 cells at high E/T ratio (10/1) independently of HER2 status while trastuzumabmediated ADCC proved to be much less efficient than against HER2 ${ }^{\text {high }}$ cells. NK cell activation mediated by HER2bsFab upon trastuzumab-refractive cell engagement still remained stronger than that mediated by trastuzumab as demonstrated by higher secretion levels of granzyme $\mathrm{B}$ and pro-inflammatory cytokines. Taken together, these results suggest that comparatively to trastuzumab, the threshold of HER2 density on target cells required for inducing HER2bsFab-mediated NK cell activation and ADCC was lower, maybe due to its enhanced Fc $\gamma$ RIIIA binding.

Interestingly, at low $\mathrm{E} / \mathrm{T}$ ratio $(1: 1)$, a condition closer to the situation at the tumor site, HER2bsFab still remained significantly more potent than trastuzumab for inducing MCF-7 lysis, underlying the potential benefit of HER2bsFab against tumors expressing low HER2 levels in vivo.

Taking benefit from the fact that HER2bsFab can bind mouse resident immune cells including NK cells, macrophages and neutrophils, we demonstrated that HER2bsFab triggers a potent ADCC activity in vivo. In NMRI Nude mice with established HER2 ${ }^{\text {high }}$ BT 474 xenograft, HER2bsFab displayed the same potential as trastuzumab at inhibiting tumor growth. In the absence of anti-proliferative properties, the HER2bsFab-mediated effects on tumor growth can exclusively be attributed to ADCC and these effects are target-restricted since an irrelevant bsFab had no impact on tumor growth. Although the toxicity of the HER2bsFab remains to be further evaluated, it must be pointed out that, in all in vivo studies, no apparent detrimental off target toxicity was observed as monitored by animal survival and weight curves despite repeated injections. Along this line, we showed that, in vitro, HER2bsFab was unable to elicit ADCC against the non-tumorigenic human mammary epithelial cells

\section{(hTERT-HME1).}

In a context of low-HER2-overexpressing and trastuzumab-refractive tumors, the potency of bsFab was tested in NMRI Nude mice with established MCF7 or JIMT-1 xenografts. Consistent with several studies showing the ability of trastuzumab to inhibit outgrowth of detectable JIMT-1 tumors [54, 56], a moderate growth inhibition was observed with trastuzumab. Unexpectedly, while a stronger inhibitory effect of bsFab could have been expected based on in vitro ADCC assays, HER2bsFab reduced JIMT-1 tumor growth, closely approaching significance $(\mathrm{P}=0.057)$. This finding could be related to the observation that the difference in ADCC activity between the two antibodies was abrogated, in vitro, at low E/T ratio (1:1) with this cell line. In contrast, a more striking difference was observed on established MCF-7 xenografts. Unlike trastuzumab that, as described in the literature, had no effect against MCF-7 tumors, HER2bsFab induced a significant slowdown of tumor growth suggesting that HER2bsFab could provide a clinical benefit in the case of both high- and low-HER2-overexpressing breast cancers.

Our results are in line with recent reports on the benefit of enhancing trastuzumab affinity for Fc $\gamma$ RIIIA on its antitumor activity in vivo $[15,16]$ and emphasize the role of ADCC as mechanism of action in the in vivo antitumor effects of ADCC-promoting antibodies in solid tumors. Moreover, by targeting an epitope on Fc $\gamma$ RIIIA distant from the Fc binding site, HER2bsFab completely bypasses the Fc $\gamma$ RIIIA-158 polymorphism issue that restricts the therapeutic efficiency of trastuzumab [13] for all FcyRIIIA-158 F carriers. HER2bsFab could thus represent an interesting approach for an efficient HER2-targeting treatment independent of both patient Fc $\gamma$ RIIIA-158 phenotype and HER2 status. Recently, clinical evidences have been reported on the benefit of multiple HER2-targeted therapies [57, 58]. In this regard, the different epitope specificities of HER2bsFab for both HER2 and FcyRIIIA compared with trastuzumab and pertuzumab [31, 45] could be of clinical interest for combinatorial therapies, as no interference in binding and killing efficacy should be expected. Finally, in addition to patients with low HER2 IHC score, patients experiencing tumor progression during trastuzumab-based treatment may also benefit from HER2bsFab.

In conclusion, we have designed a bispecific antibody displaying a moderate affinity for the tumortargeted antigen and a unique, specific and high Fc $\gamma$ RIIIbinding affinity using ADCC as major mechanism of action. Endowed with a high potential to inhibit HER2 ${ }^{\text {high }}$ tumor growth, HER2bsFab also overcomes in vitro and in vivo limitations associated with the threshold of HER2 expression level on target cells and with NK cell polymorphism for eliciting efficient anti-tumor activity. This study raises the perspective to enable the treatment of a broader population of patients than that eligible with current HER2-targeted therapies. 


\section{MATERIALS AND METHODS}

\section{Construction and production of HER2bsFab}

The anti-HER2 $x$ Fc $\gamma$ RIII bispecific antibody was constructed by cloning cDNA of the anti-HER2 sdAb (HER2.C7b) [59] into the expression vector pBAT14 upstream the anti-Fc $\gamma$ RIII sdAb (CD16.21) cDNA [30]. The resulting bispecific antibody, named HER2bsFab, was produced in E.coli (DH5 $\alpha$ strain) periplasm and purified as previously described [30]. Endotoxin concentration was checked using the Pierce LAL Chromogenic Endotoxin Quantitation Kit (Thermo Scientific). Commercial trastuzumab (Herceptin ${ }^{\circledR}$, Roche) was a kind gift from TrGET platform (U1068 INSERM, Marseille, France).

\section{Effector cells and target cell lines}

Breast cancer cell lines SK-OV-3 (ATCC HTB-77), SK-BR-3 (ATCC HTB-30), BT-474 (ATCC HTB-20), MCF-7 (ATCC HTB-22) and the immortalized epithelial cell line hTERT-HME-1 (ATCC CRL-401) were purchased from ATCC and JIMT-1 (ACC 589) cell line from DSMZ. Human FcyRIIIA transfected Jurkat lymphoma T cells (Jurkat-huFc $\gamma$ RIIIA cells) were a gift of Pr. Eric Vivier (Marseille, France) and were not authenticated. Stably transfected $\mathrm{CHO}$ cells expressing FLAG-tagged human Fc $\gamma$ RI (CNCM I-4383), Fc $\gamma$ RIIA-131 H (CNCM I-4384), Fc $\gamma$ RIIA-131 R (CNCM I-4385), Fc $\gamma$ RIIB (CNCM I-4386), Fc $\gamma$ RIIC (CNCM I-4387), Fc $\gamma$ RIIIA-158 F/F (CNCM I-4388), Fc $\gamma$ RIIIA-158 V/V (CNCM I-4389), Fc $\gamma$ RIIIB/NA1 (CNCM I-4390), Fc $\gamma$ RIIIB/NA2 (CNCM I-4391), Fc $\gamma$ RIIIB/SH (CNCM I-4392) were provided by Collection Nationale de Cultures de Microorganismes (CNCM, Institut Pasteur, France) [60]. Stably transfected $\mathrm{CHO}$ cells expressing FLAG-tagged mouse Fc $\gamma \mathrm{Rs}$ were reported before [61]. Human peripheral blood mononuclear cells (PBMCs) were isolated from fresh peripheral blood of healthy donors (Etablissement Français du Sang (EFS), Marseille, France) by Ficoll LSM 1077 (PAA) gradient centrifugation. All donors were of Fc $\gamma$ RIIIA-158 F/F or F/V phenotype unless otherwise stated. NK cells were isolated as previously described [30]. Frozen PBMCs from Fc $\gamma$ RIIIA-158 V/V, F/F or V/F donors were kindly provided by Dr. Christophe Picard (EFS, Marseille, France).

\section{Characterization of HER2bsFab by fluorescence cytometry}

HER2 binding capacity of tumor cell lines was quantified by DAKO QIFIKIT (DAKO Cytomation), according to the manufacturer's protocol using $\mathrm{mAb}$
ER-23 (Santa Cruz) as primary antibody. HER2 quantity was expressed as specific antibody-binding capacity units after subtraction of isotype control (mouse IgG2b) background. For binding experiments, HER2bsFab and trastuzumab were biotinylated in vitro using Ez-link micro NMHS-PEO4-biotinylation kit (Perbio science). The impact of biotinylation on antigen binding was checked by comparing binding activities of biotinylated antibodies and their unlabeled counterparts by flow cytometry. Binding and apparent affinities were determined by flow cytometry as previously described [59] using $2 \times 10^{5}$ JurkathuFc $\gamma$ RIIIA, SK-BR-3, stably transfected CHO cells expressing FLAG-tagged human or mouse Fc $\gamma$ Rs and biotinylated antibodies ( $0.05 \mathrm{nM}$ to $2000 \mathrm{nM})$. Stability assays in human serum were performed as previously described [30] for 21 days with biotinylated antibodies. Competition assays with endogenous IgGs were performed by incubating Jurkat-huFcyRIIIA cells in the presence of human serum ( 20 or $100 \%$ ) and sub-saturating concentration of biotinylated HER2bsFab $(50 \mathrm{nM})$ or trastuzumab $(200 \mathrm{nM})$. Bound antibodies were detected by flow cytometry using PE-labeled streptavidin [30].

\section{Rosette forming cell assay}

Rosette forming cell assays were performed as previously described [30]. SK-OV-3 cells $\left(5 \times 10^{6}\right)$ were labeled for $10 \mathrm{~min}$ at $37^{\circ} \mathrm{C}$ with $20 \mu \mathrm{M}$ CellTrace ${ }^{\mathrm{TM}}$ CFSE (Invitrogen) in PBS $/ 0.1 \%$ BSA and JurkathuFc $\gamma$ RIIIA cells $\left(5 \times 10^{6}\right)$ for $30 \mathrm{~min}$ at $37^{\circ} \mathrm{C}$ with $100 \mu \mathrm{M}$ CellTracker ${ }^{\mathrm{TM}}$ Red CMTPX (Invitrogen).

\section{In vitro viability assays}

Target cells $\left(5 \times 10^{3}\right.$ cells) were seeded on 96-well plates, incubated overnight for cell attachment and treated or not with increasing concentrations $(0.05$ to $500 \mathrm{nM}$ ) of trastuzumab or HER2bsFab. After 3, 5 and 7 days, cell viability was quantified with CellTiter-Glo Luminescent Cell Viability Assay according to manufacturer's protocol (Promega). Percent viability was calculated as follows: $\left(\mathrm{T}_{\mathrm{Ab}} \times 100\right) / \mathrm{T}$ with $\mathrm{T}=$ Non-treated target cells luminescent signal, and $\mathrm{T}_{\mathrm{Ab}}=$ Target cells + Antibody luminescent signal. All procedures were done in triplicate.

\section{MAPK and Akt activation}

After an 8hr-incubation in the absence or presence of $200 \mathrm{nM}$ trastuzumab or HER2bsFab, SK-BR-3 cell lysates $(25 \mu \mathrm{g})$ were separated by SDS-PAGE under reducing conditions. Western blots were probed with antiAkt (11E7, 1/1000), anti-pAkt (D9E, 1/2000), anti-MAPK (137F5, 1/1000) and anti-pMAPK (20G11, 1/1000) antibodies (Cell Signaling Technology) and anti-rabbit (sc- 
2004, 1/5000, Santa Cruz Biotechnology) or anti-mouse (A2304, 1/5000, Sigma-Aldrich) horseradish peroxidase (HRP)-conjugate secondary antibodies (sc-2004, Santa Cruz Biotechnology) for detection. $\beta$-tubulin detected with anti-tubulin (TUB 2.1, 1/4000, Sigma Aldrich) was used as protein loading control.

\section{In vitro $\mathrm{ADCC}$ assays}

Assays were performed as previously described [30]. Target cell viability was quantified using CellTiterGlo Luminescent Cell Viability Assay. Percent cytotoxicity was calculated as follows: $\left[\mathrm{T}-\left(\mathrm{T}_{\mathrm{EAb}}-\mathrm{E}\right)\right] /\left[\left(\mathrm{T}-\left(\mathrm{T}_{\mathrm{dead}}-\mathrm{E}\right)\right]\right.$ $\times 100$ with $\mathrm{T}=$ Target luminescent signal, $\mathrm{E}=$ effector luminescent signal, $\mathrm{T}_{\text {dead }}=$ luminescent signal of target cells lysed with $1 \%$ Triton X100 solution and $\mathrm{T}_{\mathrm{EAb}}=$ Target + Effector + Antibody luminescent signal.

\section{NK activation assays}

Supernatants were harvested from ADCC assays and frozen at $-20^{\circ} \mathrm{C}$. Secreted human IFN $\gamma$ and TNF $\alpha$ were measured by ELISA using the READY-SET-GO human IFN $\gamma$ or TNF $\alpha$ kits as described by the manufacturer (eBioscience). Secreted human granzyme B was measured by ELISA using the Human Granzyme B Platinum ELISA kit (eBioscience). Cell surface expression of CD69 on harvested NK cells was analyzed by flow cytometry after labeling with an APC-conjugated anti-CD69 IgG (Miltenyi).

\section{Tumor growth studies}

NMRI Nude mice were subcutaneously injected with $10^{7}$ cells in a $1 / 2(\mathrm{v} / \mathrm{v})$ Matrigel/PBS suspension (BD Biosciences). When tumors reached an average of 180-250 $\mathrm{mm}^{3}$, mice were randomly divided into treatment groups $(\mathrm{n}=6)$. HER $2 \mathrm{bsFab}(5 \mathrm{mg} / \mathrm{kg})$ and negative controls (saline buffer or irrelevant bsFab targeted to mesothelin $(5 \mathrm{mg} / \mathrm{kg}))$ were given intraperitoneally (i.p.) three times per week and trastuzumab $(5 \mathrm{mg} / \mathrm{kg})$ i.p. twice weekly. All experiments were performed in agreement with the French Animal Protection Law with the permission of local authorities

\section{Statistical analysis}

All data are presented as mean \pm SEM. Statistical analysis of in vitro data was performed by Student's unpaired t. In vivo data were analyzed by One-Way ANOVA test. Values of $\mathrm{P}<0.05$ were considered significant.

Material and Methods are further detailed in the supplementary material.

\section{ACKNOWLEDGEMENTS}

We are greatly indebted to Rémy Castellano, Yves Collette, Armelle Goubard and Laurent Pouyet of the TrGET preclinical assay platform (U1068 INSERM, Marseille, France) for their precious technical assistance with xenografted models. We also thank Dr Picard (EFS, Marseille) for providing NK cells of different Fc $\gamma$ RIIIA-158 polymorphism, the cell culture platform and the mice facilities of Marseille-Luminy (France). This work was supported by INSERM, CNRS and INSERM-Transfert (Procop). Marc Turini received funding from the European Commission through the FP7 Cooperation Program, grant no. NMP-2009-4.0-3-246479 NAMDIATREAM FP7

\section{AUTHOR CONTRIBUTIONS}

The study was conceived and designed by M.T, D.B and B.K with contribution from P.C. All data were generated by M.T with contribution from B.K for in vivo studies. Data analysis were performed by M.T and B.K with contribution from P.C, D.B and P.B for binding experiments on FcgR. P.B provided the stably transfected $\mathrm{CHO}$ cells expressing human or mouse FLAG-tagged Fc $\gamma$ R. The manuscript was written by M.T, P.C and B.K and reviewed by D.B and P.B.

\section{CONFLICT OF INTEREST}

The authors declare that they have no conflict of interest.

\section{REFERENCES}

1. Yarden Y. Biology of HER2 and its importance in breast cancer. Oncology. 2001; 61 Suppl 2:1-13.

2. Vogel CL, Cobleigh MA, Tripathy D, Gutheil JC, Harris LN, Fehrenbacher L, Slamon DJ, Murphy M, Novotny WF, Burchmore M, Shak S, Stewart SJ and Press M. Efficacy and safety of trastuzumab as a single agent in first-line treatment of HER2-overexpressing metastatic breast cancer. J Clin Oncol. 2002; 20(3):719-726.

3. Slamon D and Pegram M. Rationale for trastuzumab (Herceptin) in adjuvant breast cancer trials. Semin Oncol. 2001; 28(1 Suppl 3):13-19.

4. Rodrigues MJ, Wassermann J, Albiges L, Brain E, Delaloge S, Stevens D, Guinebretiere JM, Mathieu MC, Kirova Y, Guillot E, Vincent-Salomon A and Cottu PH. Trastuzumab treatment in $\mathrm{t} 1 \mathrm{ab}$, node-negative, human epidermal growth factor receptor 2-overexpressing breast carcinomas. J Clin Oncol. 2010; 28(28):e541-542.

5. Kruser TJ and Wheeler DL. Mechanisms of resistance to HER family targeting antibodies. Exp Cell Res. 2010; 
316(7):1083-1100.

6. Nahta R and Esteva FJ. Herceptin: mechanisms of action and resistance. Cancer Lett. 2006; 232(2):123-138.

7. Valabrega G, Montemurro F and Aglietta M. Trastuzumab: mechanism of action, resistance and future perspectives in HER2-overexpressing breast cancer. Ann Oncol. 2007; 18(6):977-984.

8. Spiridon CI, Guinn S and Vitetta ES. A comparison of the in vitro and in vivo activities of $\operatorname{IgG}$ and $\mathrm{F}(\mathrm{ab}$ ') 2 fragments of a mixture of three monoclonal anti-Her-2 antibodies. Clin Cancer Res. 2004; 10(10):3542-3551.

9. Clynes RA, Towers TL, Presta LG and Ravetch JV. Inhibitory $\mathrm{Fc}$ receptors modulate in vivo cytotoxicity against tumor targets. Nat Med. 2000; 6(4):443-446.

10. Albanesi M, Mancardi DA, Jonsson F, Iannascoli B, Fiette L, Di Santo JP, Lowell CA and Bruhns P. Neutrophils mediate antibody-induced antitumor effects in mice. Blood. 2013; 122(18):3160-3164.

11. Arnould L, Gelly M, Penault-Llorca F, Benoit L, Bonnetain F, Migeon C, Cabaret V, Fermeaux V, Bertheau P, Garnier J, Jeannin JF and Coudert B. Trastuzumab-based treatment of HER2-positive breast cancer: an antibody-dependent cellular cytotoxicity mechanism? Br J Cancer. 2006; 94(2):259-267.

12. Varchetta S, Gibelli N, Oliviero B, Nardini E, Gennari R, Gatti G, Silva LS, Villani L, Tagliabue E, Menard S, Costa A and Fagnoni FF. Elements related to heterogeneity of antibody-dependent cell cytotoxicity in patients under trastuzumab therapy for primary operable breast cancer overexpressing Her2. Cancer Res. 2007; 67(24):1199111999.

13. Musolino A, Naldi N, Bortesi B, Pezzuolo D, Capelletti M, Missale G, Laccabue D, Zerbini A, Camisa R, Bisagni G, Neri TM and Ardizzoni A. Immunoglobulin G fragment $C$ receptor polymorphisms and clinical efficacy of trastuzumab-based therapy in patients with HER-2/ neu-positive metastatic breast cancer. J Clin Oncol. 2008; 26(11):1789-1796.

14. Park S, Jiang Z, Mortenson ED, Deng L, Radkevich-Brown O, Yang X, Sattar H, Wang Y, Brown NK, Greene M, Liu Y, Tang J, Wang S and Fu YX. The therapeutic effect of anti-HER2/neu antibody depends on both innate and adaptive immunity. Cancer Cell. 2010; 18(2):160-170.

15. Junttila TT, Parsons K, Olsson C, Lu Y, Xin Y, Theriault J, Crocker L, Pabonan O, Baginski T, Meng G, Totpal K, Kelley RF and Sliwkowski MX. Superior in vivo efficacy of afucosylated trastuzumab in the treatment of HER2amplified breast cancer. Cancer Res. 2010; 70(11):44814489.

16. Nordstrom JL, Gorlatov S, Zhang W, Yang Y, Huang L, Burke S, Li H, Ciccarone V, Zhang T, Stavenhagen J, Koenig S, Stewart SJ, Moore PA, Johnson S and Bonvini E. Anti-tumor activity and toxicokinetics analysis of MGAH22, an anti-HER2 monoclonal antibody with enhanced Fcgamma receptor binding properties. Breast Cancer Res. 2011; 13(6):R123.

17. Jaime-Ramirez AC, Mundy-Bosse BL, Kondadasula S, Jones NB, Roda JM, Mani A, Parihar R, Karpa V, Papenfuss TL, LaPerle KM, Biller E, Lehman A, Chaudhury AR, Jarjoura D, Burry RW and Carson WE, 3rd. IL-12 enhances the antitumor actions of trastuzumab via NK cell IFNgamma production. J Immunol. 2011; 186(6):3401-3409.

18. Welslau M, Dieras V, Sohn JH, Hurvitz SA, Lalla D, Fang L, Althaus B, Guardino E and Miles D. Patient-reported outcomes from EMILIA, a randomized phase 3 study of trastuzumab emtansine (T-DM1) versus capecitabine and lapatinib in human epidermal growth factor receptor 2-positive locally advanced or metastatic breast cancer. Cancer. 2013.

19. Lewis Phillips GD, Fields CT, Li G, Dowbenko D, Schaefer G, Miller KD, Andre F, Burris HA, 3rd, Albain KS, Harbeck N, Dieras V, Crivellari D, Fang L, Guardino E, Olsen SR, Crocker LM, et al. Dual targeting of HER2positive cancer with trastuzumab-emtansine (T-DM1) and pertuzumab: critical role for neuregulin blockade in antitumor response to combination therapy. Clin Cancer Res. $2013 ; 15: 456-468$.

20. Diermeier-Daucher S, Ortmann O, Buchholz S and Brockhoff G. Trifunctional antibody ertumaxomab: Nonimmunological effects on Her2 receptor activity and downstream signaling. MAbs. 2012; 4(5):614-622.

21. Chames P and Baty D. Bispecific antibodies for cancer therapy: the light at the end of the tunnel? MAbs. 2009; 1(6):539-547.

22. Kontermann R. Dual targeting strategies with bispecific antibodies. MAbs. 2012; 4(2):182-197.

23. Topp MS, Gokbuget N, Zugmaier G, Degenhard E, Goebeler ME, Klinger M, Neumann SA, Horst HA, Raff T, Viardot A, Stelljes M, Schaich M, Kohne-Volland R, Bruggemann M, Ottmann OG, Burmeister T, et al. Longterm follow-up of hematologic relapse-free survival in a phase 2 study of blinatumomab in patients with MRD in B-lineage ALL. Blood. 2012; 120(26):5185-5187.

24. Linke R, Klein A and Seimetz D. Catumaxomab: clinical development and future directions. MAbs. 2010; 2(2):129136.

25. Frankel SR and Baeuerle PA. Targeting T cells to tumor cells using bispecific antibodies. Curr Opin Chem Biol. 2013; 17(3):385-392.

26. Bruhns P. Properties of mouse and human IgG receptors and their contribution to disease models. Blood. 2012; 119(24):5640-5649.

27. Weiskopf K, Ring AM, Schnorr PJ, Volkmer JP, Volkmer AK, Weissman IL and Garcia KC. Improving macrophage responses to therapeutic antibodies by molecular engineering of SIRPalpha variants. Oncoimmunology. 2013; 2(9):e25773.

28. Thakur A and Lum LG. Cancer therapy with bispecific 
antibodies: Clinical experience. Curr Opin Mol Ther. 2010; 12(3):340-349.

29. Reusch U, Burkhardt C, Fucek I, Le Gall F, Le Gall M, Hoffmann K, Knackmuss SH, Kiprijanov S, Little M and Zhukovsky EA. A novel tetravalent bispecific TandAb (CD30/CD16A) efficiently recruits NK cells for the lysis of CD30+ tumor cells. MAbs. 2014; 6(3):728-739.

30. Rozan C, Cornillon A, Petiard C, Chartier M, Behar G, Boix C, Kerfelec B, Robert B, Pelegrin A, Chames P, Teillaud JL and Baty D. Single-domain antibody-based and linker-free bispecific antibodies targeting FcgammaRIII induce potent antitumor activity without recruiting regulatory T cells. Mol Cancer Ther. 2013; 12(8):1481-1491.

31. Behar G, Siberil S, Groulet A, Chames P, Pugniere M, Boix C, Sautes-Fridman C, Teillaud JL and Baty D. Isolation and characterization of anti-FcgammaRIII (CD16) llama singledomain antibodies that activate natural killer cells. Protein Eng Des Sel. 2008; 21(1):1-10.

32. Tanner M, Kapanen AI, Junttila T, Raheem O, Grenman S, Elo J, Elenius K and Isola J. Characterization of a novel cell line established from a patient with Herceptin-resistant breast cancer. Mol Cancer Ther. 2004; 3(12):1585-1592.

33. Nagy P, Friedlander E, Tanner M, Kapanen AI, Carraway KL, Isola J and Jovin TM. Decreased accessibility and lack of activation of ErbB2 in JIMT-1, a herceptin-resistant, MUC4-expressing breast cancer cell line. Cancer Res. 2005; 65(2):473-482.

34. Lacroix M and Leclercq G. Relevance of breast cancer cell lines as models for breast tumours: an update. Breast Cancer Res Treat. 2004; 83(3):249-289.

35. Preithner S, Elm S, Lippold S, Locher M, Wolf A, da Silva AJ, Baeuerle PA and Prang NS. High concentrations of therapeutic IgG1 antibodies are needed to compensate for inhibition of antibody-dependent cellular cytotoxicity by excess endogenous immunoglobulin G. Mol Immunol. 2006; 43(8):1183-1193.

36. Shields RL, Namenuk AK, Hong K, Meng YG, Rae J, Briggs J, Xie D, Lai J, Stadlen A, Li B, Fox JA and Presta LG. High resolution mapping of the binding site on human IgG1 for Fc gamma RI, Fc gamma RII, Fc gamma RIII, and FcRn and design of IgG1 variants with improved binding to the Fc gamma R. J Biol Chem. 2001; 276(9):6591-6604.

37. Shields RL, Lai J, Keck R, O'Connell LY, Hong K, Meng YG, Weikert SH and Presta LG. Lack of fucose on human IgG1 N-linked oligosaccharide improves binding to human Fcgamma RIII and antibody-dependent cellular toxicity. J Biol Chem. 2002; 277(30):26733-26740.

38. Lazar GA, Dang W, Karki S, Vafa O, Peng JS, Hyun L, Chan C, Chung HS, Eivazi A, Yoder SC, Vielmetter J, Carmichael DF, Hayes RJ and Dahiyat BI. Engineered antibody Fc variants with enhanced effector function. Proc Natl Acad Sci U S A. 2006; 103(11):4005-4010.

39. Keler T, Graziano RF, Mandal A, Wallace PK, Fisher J, Guyre PM, Fanger MW and Deo YM. Bispecific antibody-dependent cellular cytotoxicity of HER2/neuoverexpressing tumor cells by Fc gamma receptor type I-expressing effector cells. Cancer Res. 1997; 57(18):40084014.

40. Wozniak-Knopp G, Bartl S, Bauer A, Mostageer M, Woisetschlager M, Antes B, Ettl K, Kainer M, Weberhofer G, Wiederkum S, Himmler G, Mudde GC and Ruker F. Introducing antigen-binding sites in structural loops of immunoglobulin constant domains: Fc fragments with engineered HER2/neu-binding sites and antibody properties. Protein Eng Des Sel. 2010; 23(4):289-297.

41. Grabert RC, Cousens LP, Smith JA, Olson S, Gall J, Young WB, Davol PA and Lum LG. Human T cells armed with Her2/neu bispecific antibodies divide, are cytotoxic, and secrete cytokines with repeated stimulation. Clin Cancer Res. 2006; 12(2):569-576.

42. Jager M, Schoberth A, Ruf P, Hess J and Lindhofer H. The trifunctional antibody ertumaxomab destroys tumor cells that express low levels of human epidermal growth factor receptor 2. Cancer Res. 2009; 69(10):4270-4276.

43. Borghaei H, Alpaugh RK, Bernardo P, Palazzo IE, Dutcher JP, Venkatraj U, Wood WC, Goldstein L and Weiner LM. Induction of adaptive Anti-HER2/neu immune responses in a Phase $1 \mathrm{~B} / 2$ trial of $2 \mathrm{~B} 1$ bispecific murine monoclonal antibody in metastatic breast cancer (E3194): a trial coordinated by the Eastern Cooperative Oncology Group. J Immunother. 2007; 30(4):455-467.

44. Weiner LM, Holmes M, Adams GP, LaCreta F, Watts P and Garcia de Palazzo I. A human tumor xenograft model of therapy with a bispecific monoclonal antibody targeting c-erbB-2 and CD16. Cancer Res. 1993; 53(1):94-100.

45. Even-Desrumeaux K, Fourquet P, Secq V, Baty D and Chames P. Single-domain antibodies: a versatile and rich source of binders for breast cancer diagnostic approaches. Mol Biosyst. 2012; 8(9):2385-2394.

46. Rudnick SI, Lou J, Shaller CC, Tang Y, Klein-Szanto AJ, Weiner LM, Marks JD and Adams GP. Influence of affinity and antigen internalization on the uptake and penetration of Anti-HER2 antibodies in solid tumors. Cancer Res. 2011; 71(6):2250-2259.

47. Adams GP, Schier R, McCall AM, Simmons HH, Horak EM, Alpaugh RK, Marks JD and Weiner LM. High affinity restricts the localization and tumor penetration of single-chain fv antibody molecules. Cancer Res. 2001; 61(12):4750-4755.

48. Cao Y, Marks JD, Huang Q, Rudnick SI, Xiong C, Hittelman WN, Wen X, Marks JW, Cheung LH, Boland K, Li C, Adams GP and Rosenblum MG. Single-chain antibody-based immunotoxins targeting Her2/neu: design optimization and impact of affinity on antitumor efficacy and off-target toxicity. Mol Cancer Ther. 2012; 11(1):143153.

49. Overdijk MB, Verploegen S, van den Brakel JH, Lammerts van Bueren JJ, Vink T, van de Winkel JG, Parren PW and Bleeker WK. Epidermal growth factor receptor (EGFR) 
antibody-induced antibody-dependent cellular cytotoxicity plays a prominent role in inhibiting tumorigenesis, even of tumor cells insensitive to EGFR signaling inhibition. J Immunol. 2011; 187(6):3383-3390.

50. Sergina NV, Rausch M, Wang D, Blair J, Hann B, Shokat KM and Moasser MM. Escape from HER-family tyrosine kinase inhibitor therapy by the kinase-inactive HER3. Nature. 2007; 445(7126):437-441.

51. Nahta R, Yuan LX, Zhang B, Kobayashi R and Esteva FJ. Insulin-like growth factor-I receptor/human epidermal growth factor receptor 2 heterodimerization contributes to trastuzumab resistance of breast cancer cells. Cancer Res. 2005; 65(23):11118-11128.

52. Weiner LM, Alpaugh RK, Amoroso AR, Adams GP, Ring DB and Barth MW. Human neutrophil interactions of a bispecific monoclonal antibody targeting tumor and human Fc gamma RIII. Cancer Immunol Immunother. 1996; 42(3):141-150.

53. Fauriat C, Long EO, Ljunggren HG and Bryceson YT. Regulation of human NK-cell cytokine and chemokine production by target cell recognition. Blood. 2010; 115(11):2167-2176.

54. Damiano V, Garofalo S, Rosa R, Bianco R, Caputo R, Gelardi T, Merola G, Racioppi L, Garbi C, Kandimalla ER, Agrawal S and Tortora G. A novel toll-like receptor 9 agonist cooperates with trastuzumab in trastuzumabresistant breast tumors through multiple mechanisms of action. Clin Cancer Res. 2009; 15(22):6921-6930.

55. Osborne CK, Hobbs K and Trent JM. Biological differences among MCF-7 human breast cancer cell lines from different laboratories. Breast Cancer Res Treat. 1987; 9(2):111-121.

56. Barok M, Isola J, Palyi-Krekk Z, Nagy P, Juhasz I, Vereb G, Kauraniemi P, Kapanen A, Tanner M and Szollosi J. Trastuzumab causes antibody-dependent cellular cytotoxicity-mediated growth inhibition of submacroscopic JIMT-1 breast cancer xenografts despite intrinsic drug resistance. Mol Cancer Ther. 2007; 6(7):2065-2072.

57. Baselga J, Gelmon KA, Verma S, Wardley A, Conte P, Miles D, Bianchi G, Cortes J, McNally VA, Ross GA, Fumoleau P and Gianni L. Phase II trial of pertuzumab and trastuzumab in patients with human epidermal growth factor receptor 2-positive metastatic breast cancer that progressed during prior trastuzumab therapy. J Clin Oncol. 2010; 28(7):1138-1144.

58. Cortes J, Fumoleau P, Bianchi GV, Petrella TM, Gelmon K, Pivot X, Verma S, Albanell J, Conte P, Lluch A, Salvagni S, Servent V, Gianni L, Scaltriti M, Ross GA, Dixon J, et al. Pertuzumab monotherapy after trastuzumab-based treatment and subsequent reintroduction of trastuzumab: activity and tolerability in patients with advanced human epidermal growth factor receptor 2-positive breast cancer. J Clin Oncol. 2012; 30(14):1594-1600.

59. Even-Desrumeaux $\mathrm{K}$ and Chames $\mathrm{P}$. Affinity determination of biotinylated antibodies by flow cytometry. Methods Mol Biol. 2012; 907:443-449.
60. Bruhns P, Iannascoli B, England P, Mancardi DA, Fernandez N, Jorieux $S$ and Daeron M. Specificity and affinity of human Fcgamma receptors and their polymorphic variants for human IgG subclasses. Blood. 2009; 113(16):3716-3725.

61. Mancardi DA, Iannascoli B, Hoos S, England P, Daeron $\mathrm{M}$ and Bruhns P. FcgammaRIV is a mouse IgE receptor that resembles macrophage FcepsilonRI in humans and promotes IgE-induced lung inflammation. J Clin Invest. 2008; 118(11):3738-3750. 